\title{
Different Ways of Perceiving the Aging Process: Social Behaviors of Women and Men in Relation to Age Discrimination
}

\author{
Alfonso J. García, Yolanda Troyano \\ Department Social Psychology, Faculty of Psychology, Seville, Spain \\ Email: alfonsoj@us.es
}

Received December 21 ${ }^{\text {st }}$ 2012; revised January $19^{\text {th }}$, 2013; accepted February $17^{\text {th }}, 2013$

\begin{abstract}
Based on the original survey "Relating to Older People Evaluation" (ROPE) by Cherry and Palmore (2008), we have elaborated the instrument Evaluation for Older Adults that consists of 20 items. In this project, we intend on studying the positive and negative behaviors which people have been able to internalize during their daily life, as well as a previous psychometric analysis about the validity of the instrument. The sample is formed by, on one side, students of Psycho pedagogy, and the other side, older students that belong to the Class of Experience of the University of Seville. The results obtained suggest that the majority of the people take into consideration the positive behaviors, and both the young and the older adults reinforce the behaviors of and toward the older adults. It is important to highlight the significant differences as far as gender in relation to the internalization of positive behaviors, being more frequent in women than in men. In the discussion, we analyze the implications about social perception towards older people as a social phenomenon, as well as the strategies to reduce the negative behaviors towards older people in daily life.
\end{abstract}

Keywords: Older People; Young People; Social Perception; Discrimination

\section{Introduction}

The majority of people are familiar with the concept of age discrimination, which refers to any type of prejudice or discrimination based on chronological age. Butler (1969) was the first to coin this term; and since then, a wide range of experimental evidence documents the frequent and generalized presence of studies about discrimination based on reasons of age in our society today (Palmore, 1999, 2001). From a psychosocial perspective, age can also influence implicit beliefs related to the competency of older persons, as well as the configuration of stereotypes (Levy, 2001). Most authors agree that we live in a society oriented towards the youth, where the diverse ways of discrimination based on reasons of age are widespread (Kelchner, 1999; Palmore, Branch, \& Harris 2006). In fact, many perceived behaviors such as demonstrating courtesy towards older persons can be precisely manifestations of discrimination, based on the expression of stereotypical attitudes (Palmore, 1999).

The purpose of the present study is to develop a profile of older persons in relation to the positive and negative behaviors that are manifested towards them during their daily life. In the scientific literature, various investigations about age discrimination can be found, such as a scale that measures attitudes towards older persons (Kogan, 1961); or the Semantic Differential about Aging (Rosecranz \& McNevin, 1969). Recently, a questionnaire has been elaborated in order to measure the prejudice beliefs and the discrimination towards older persons (Palmore, 2001). This way, it can be demonstrated the importance of taking into account the incidence and the prevalence of age discrimination in society in general.

In this way a cross-sectional study examined the associations among perceived vulnerability to disease, aging knowledge, and ageism (positive and negative) in a sample of undergraduate students enrolled in a human development course. Perceived vulnerability to disease and aging knowledge were associated with self-reported ageist behaviors. Undergraduates who viewed themselves as more susceptible to disease and knew less about the aging process tended to report more negative ageist behavior. Sex moderated the association between aging knowledge and ageist behavior, indicating the association was stronger for males (Stahl \& Metzger, 2012).

Other study is focused on self-reported ageism in college students and social service providers using the Relating to Older People Evaluation (Cherry \& Palmore, 2008). Participants included undergraduate and graduate social work students and practicing social service providers in the nursing home and mental health setting. Findings indicate that people of varying educational backgrounds and occupational experience in social services readily admit to positive ageist behaviors. Item analyses revealed similarities and differences between groups in the most and least frequent forms of ageism endorsed (Allen, Cherry, \& Palmore, 2009).

In this article, we present an analysis of the frequency and the types of behaviors towards older persons in general. The used survey contains 20 types of behaviors related to older people: 6 items deal with age discrimination in a positive sense and 14 are negative. As an example, many items are included, such as: "Maintains the door open for older people as a result of their age;" or "Votes for an older person due to his or her age". In a negative sense, we emphasize for example: "Wishes happy birthday to older persons in order to joke about their age"; or "Votes against an older person as a result of his or her age". Palmore elaborates the topics.

The questionnaire is designed to measure the discrimination of older people in the personal sphere (negative or positive). 
The distinction between negative and positive is based on Palmore's (1999) conceptual characteristics of reasons for age discrimination. In general, elderly age discrimination in the personal sphere is based on negative stereotypes, as the difficulty in developing an active lifestyle, adopting a sedentary attitude, low self-esteem and a lower quality of life. In front of people who thinks that older people have much wisdom comes from experience developed lifespan (García, 2011).

One of the main novelty in this work is to analyze the discriminatory behavior (positive or negative) on young and elderly people. Thus, we do extensive research to seniors. Similar to Palmore in his study, we expect to answer questions like the following:

- What is the prevalence of age discriminative behaviors in the Andalucian society?

- What types of age discriminative behaviors are more frequent?

\section{Methods}

\section{Sample}

A total of 108 persons participated in this study. The participants include $4^{\text {th }}$ and $5^{\text {th }}$ year university students of Psycho pedagogy, and an older student body from the Class of the Experience of the University of Seville. Participants study at the University of Seville. They have a socio-economic mediumhigh status. Also, the sample is characterized by choosing voluntarily university studies. In the case of young people, $84 \%$ report having intergenerational relationships with grandparents or older neighbors.

The social demographic characteristics of the sample appear in Table 1.

\section{Instrument}

In this study, has been used the Relating to Older People Evaluation (Cherry \& Palmore, 2008). The ROPE is a 20-item questionnaire that measures positive and negative ageist behaviors that people engage in during everyday life.

To make the questionnaire we took the original questionnaire ROPE and has been tested for construct validity and reliability as Cronbach's alpha, resulting in an overall reliability of .83 . About the construct validity of the scale, it was evaluated by outside judges, experts in social perception, social discrimination and prejudice. The result respect to the proposed items related to the topics was a high or very high valuation for each of the items.

\section{Proceedings}

For the realization of the surveys, specific dates were programmed for the survey taker to go to the Psycho pedagogy classes and the Class of the Experience, respectively, in order to guarantee the maximum attendance of the students and to obtain a representative sample of the object of study population. Similarly, the same surveyor applied all the surveys in an attempt to homogenize the implemented instructions.

\section{Results}

\section{Frequency Analysis}

In general, the results indicate that the age discriminative behaviors are generalized and frequent in all age groups. Practically, all the survey-takers admitted one or more discriminative behaviors. In addition, the prevalence of positive behaviors appears more frequently than negative ones.

The discriminative behavior more frequently manifested through $98 \%$ of the survey-takers was "he or she asks for advice from an older person because of his or her age". Almost the same frequency is found in the other two behaviors of positive discrimination: "Enjoys conversing with older persons because of his or her age" (91\%); and "Maintains the doors open for older people as a result of their age” (86\%) (Table 2). The least frequent positive age discriminative behavior was "Votes for an older person as a result of his or her age" (23\%).

The frequency analysis of the negative behavior of age discrimination shows that $90 \%$ assert to say to an older person: "You are too old for this". This affirmation may look positive, but in reality it is negative because it implies to sub-esteem the capacities of the older person (Table 3 ). The second negative element that was more frequent (64\%) was: "When there is a slow driver in front of you, you think it must be an older person.” The three negative behaviors less frequent were: “Avoid older people because they are irritating” (17\%); "Vote against an older person because of his/her age" (19\%); and "Jokes about older people’s age” (21\%).

\section{Gender and Age Differences}

From this study, two age groups are derived: the young adults (21 - 49 years old, $n=33$ ) and middle-old age adults (50 82 years old, $n=75$ ).

Table 1.

Social demographic characteristics.

\begin{tabular}{cccccc}
\hline Group & & Age & & \multicolumn{2}{c}{ Gender } \\
\hline & M & DT & Range & Men & Women \\
Students of Educational Psychology $(\mathrm{n}=34)$ & 52.6 & 8.9 & $21-53$ & 6 & 28 \\
Students of Elderly Programs $(\mathrm{n}=74)$ & 68.3 & 9.7 & $54-82$ & 23 & 51 \\
\hline
\end{tabular}

Table 2.

Most frequency positive discrimination.

Positive Discrimination 
Table 3.

Most frequency negative discrimination.

\begin{tabular}{ccc}
\hline \multirow{2}{*}{ Behaviors of Discrimination } & \multicolumn{2}{c}{ Negative Discrimination } \\
\cline { 2 - 3 } & You are too old for this & When there is a slow driver in front of you, you think it must be an older person \\
\hline $90 \%$ & $64 \%$ \\
\hline
\end{tabular}

With this data, we find little or no significant difference between the age groups, either in the manifestation of positive or negative discrimination behaviors. Making a non-significant ANOVA confirms an effect on base to the age groups $(p=.62)$. In this manner, the way to relate to the older adults is cultural and it does not often change as the subjects' age changes. The relationship was significant in the positive discrimination behaviors $\mathrm{F}(1,108)=92.05, p<.001$.

With respect to the possible differences of gender, we foresaw that men and women would give very similar answers. Contrary to our expectations, the analysis shows an effect on the answers given by women. In fact, women show more positive discrimination behavior towards older adults than men ( $\mathrm{F}$ $(1,108)=5.41, p=.02)$, although neither men nor women differ in their perception of age discrimination negative behavior.

\section{Discussion}

We assume the fact that the majority of older adults have experienced different forms of age discrimination (Palmore, 2001, 2004). Nevertheless, until not that long ago, there was no interest to measure the frequency and the types of age discrimination behaviors. The results have shown that people of all ages admit to have age discrimination positive behavior. Similarly, it has been verified the prevalence of the positive behaviors in the women's responses.

Our first conclusion of interest from this study refers to the predominance of the positive conducts over the negative in relation to age discrimination. Therefore, we find that the used questionnaire seems to be a valid instrument to measure age discrimination behavior from a wide variety of participants.

The second interesting finding from this study has been that the young adults and the middle-old age adults have shown to have very similar age discrimination behavior. Nevertheless, the attitudes towards the age discrimination behaviors diminish with age and with more experience in life (Kalavar, 2001; Rupp, Vodanovich, \& Cred, 2005). In this sense, our results suggest that age is not a determinant factor when it comes to age discrimination behaviors.

The third interesting finding comes from the gender analysis, which reveals that women show positive age discrimination more frequently than men. In agreement with this point of view, Stuart-Hamilton \& Mahoney (2003) found that people with a better understanding of the aging process may maintain attitudes of less age discrimination.

Hence, the results from this study highlight the importance of providing information and formation about the aging process, either through a study program (like the one that the Class of Experience proposes); either through continuous educational workshops for the professionals that work with older adults. This way, educational programs and workshops that focus on improving the knowledge about the aging process are essential for the professionals that may get in contact with the older adult population, taking into consideration the demographic tendency in a continuous ascent of the older adults in our present society and in the future (Jackson, Cherry, Smitherman, \& Hawley, 2008).

In our study, there were two limitations as far as the method was concerned. First, people can deny or minimize the frequency of their behavior if they perceive it is bad or socially undesirable. In the same manner, they can exaggerate the frequency of this type of behavior if they perceive that it is socially desirable, which tends to augment the frequency of the positive elements, giving place to the phenomenon of social desirability.

Future studies must include the observation of the real behaviors or an instrument that controls such effect. Besides, it would be interesting to do a prospective analysis based on the results found in this study, which shows needs for implementing a psychosocial intervention program. This program would base its action on optimizing positives behaviors about elderly people, favoring active aging.

\section{Acknowledgements}

A. J. García and Y. Troyano thank to IMSERSO the possibility to do this work with an I + D + I project about "Quality Life and Elderly People”.

\section{REFERENCES}

Allen, P. D., Cherry, K. E., \& Palmore, E. (2009). Self-reported ageism in social work practitioners and students. Journal of Gerontological Social Work, 52, 208-218. doi:10.1080/01634370802561927

Butler, R. N. (1969). Age-ism: Another form of bigotry. Gerontologist, 9, 243-246. doi:10.1093/geront/9.4_Part 1.243

Cherry, K. E., \& Palmore , E. B. (2008). Relating to older people evaluation (ROPE): A measure of self-reported ageism. Educational Gerontology, 34, 849-861. doi:10.1080/03601270802042099

Cohen, E. S. (2001). The complex nature of ageism: What is it? Who does it? Who perceives it? The Gerontologist, 41, 576-577. doi:10.1093/geront/41.5.576

García, A. J. (2011). Variables psicosociales que inciden en la calidad de vida de los participantes en programas universitarios de mayores. Ph.D. Thesis, Seville: Seville University.

Jackson, E. M., Cherry, K. E., Smitherman, E. A., \& Hawley, K. S. (2008). Knowledge of memory aging and Alzheimer's disease in college students and mental health professionals. Aging and Mental Healthm, 12, 258-266. doi:10.1080/13607860801951861

Kalavar, J. (2001). Examining ageism: Do male and female college students differ? Educational Gerontology, 27, 507-513. doi:10.1080/036012701316894199

Kelchner, E. S. (1999). Ageism's impact and effect on society: Not just a concern for the old. Journal of Gerontological Social Work, 32, 85100. doi:10.1300/J083v32n04 07

Kogan, N. (1961). Attitudes toward old people: The development of a scale and an examination of correlates. Journal of Abnormal and Social Psychology, 62, 44-54. doi:10.1037/h0048053

Levy, B. R. (2001). Eradication of ageism requires addressing the enemy within. The Gerontologist, 41, 578-579. doi:10.1093/geront/41.5.578

Palmore, E. B. (1999). Ageism: Negative and positive. New York: 


\section{A. J. GARCÍA, Y. TROYANO}

Springer.

Palmore, E. B. (2001). The ageism survey: First findings. The Gerontologist, 41, 572-575. doi:10.1093/geront/41.5.572

Palmore, E. (2004). Ageism in Canada and the United States. Journal of Cross-Cultural Gerontology, 19, 41-46. doi:10.1023/B:JCCG.0000015098.62691.ab

Palmore, E., Branch, L., \& Harris, D. (2006). The encyclopedia of ageism. Binghamton, NY: Haworth Press.

Rosencranz, H. A., \& McNevin, T. E. (1969). A factor analysis of attitudes toward the aged. The Gerontologist, 9, 55-59.

doi:10.1093/geront/9.1.55
Rupp, D. E., Vodanovich, S. J., \& Cred, M. (2005). The multidimensional nature of ageism: Construct validity and group differences. The Journal of Social Psychology, 145, 335-362. doi:10.3200/SOCP.145.3.335-362

Stahl, S., \& Metzger, A. (2012). College students' ageist behavior: The role of aging knowledge and perceived vulnerability to disease. Gerontology \& Geriatrics Education, 2, 175-180. doi:10.1080/02701960.2012.718009

Stuart-Hamilton, I., \& Mahoney, B. (2003). Examining ageism: Do male and female college students differ? Educational Gerontology, 29, 251-260. doi:10.1080/713844305 